\title{
Rheological properties of peanut protein isolate aggregation suspension and acid-induced gel
}

\author{
Zhigang Huang ${ }^{1,2}$, Xueying Wang ${ }^{1}$, Shangyi Chi ${ }^{1}$, Zhe Hua ${ }^{3}$, Chonghao $\mathrm{Bi}^{1 *}$ \\ (1. School of Artificial Intelligence, Beijing Technology and Business University, Beijing 100048, China; \\ 2. Beijing Key Laboratory of Quality Evaluation Technology for Hygiene and Safety of Plastics, Beijing 100048, China; \\ 3. School of Mechanical and Electronic Control Engineering, Beijing Jiaotong University, Beijing 100044, China)
}

\begin{abstract}
The dynamic rheological properties of peanut protein isolate (PPI) suspension and acid-induced PPI gels were studied. In frequency sweep test, the storage modulus $\left(G^{\prime}\right)$ and the loss modulus $\left(G^{\prime \prime}\right)$ of PPI aggregation suspensions at different concentrations increased with the increase of frequency. The steady state shear flow test showed that PPI aggregation suspension had a thinning behavior of the shear, and the image of steady shear curve fitted the Carreau model. After gel formation, acid-induced PPI gels showed a typical Type I behavior (strain thinning) in strain sweep test, meaning that PPI gel got easily broken down, and there was a very small opportunity for the protein molecules to re-establish the network. Compared with the strain sweep of PPI aggregation suspensions and gels, the range of the storage modulus existed a dramatic difference, which could get about tenfold. As the frequency increased, both elasticity and viscosity increased in frequency sweep test, which indicated that the frequency dependence of the storage modulus increased with the increase of concentration. Keywords: peanut protein isolate (PPI), aggregation suspension, acid-induced PPI gel, dynamic rheological properties DOI: $10.25165 /$ j.ijabe.20211403.6021
\end{abstract}

Citation: Huang Z G, Wang X Y, Chi S Y, Hua Z, Bi C H. Rheological properties of peanut protein isolate aggregation suspension and acid-induced gel. Int J Agric \& Biol Eng, 2021; 14(3): 255-260.

\section{Introduction}

Peanut is a leguminous, annual herb, and is an important protein resource ${ }^{[1]}$. The nutritional value of peanut protein is similar to animal protein. Peanut protein contains a large number of essential amino acids. It is widely used in the food industry as a kind of plant protein resource ${ }^{[2]}$. Due to the high nutritional value, peanut protein has an attractive fragrance ${ }^{[3]}$. Peanut protein powder can be used as the main component of food and food accessories $^{[4,5]}$. Peanut protein can greatly improve the processing characteristics of food; it is also widely used in the food industry as food additives ${ }^{[6]}$. Because the peanut protein has the advantages of good anti emulsification, moisture retention, good film-forming property, and oxidation resistance, it is an ideal base material for preparing edible food fresh-keeping film ${ }^{[7]}$. The content of protein in peanut was $24 \%-36 \%$, which was next only to the protein of sesame and rape ${ }^{[8]}$. For a long time, in addition to using for food directly, peanuts are mainly used for oil extraction. The proportion of edible peanut and peanut oil in the world is $36 \%$ and $54 \%$, respectively. At present, people aim at producing high quality protein from peanuts gradually. Peanut has become an important source of edible oil and protein ${ }^{[8]}$.

$\mathrm{Bi}$ et al. ${ }^{[9]}$ took acid-induced peanut protein isolate (PPI) gel as

\section{Received date: 2020-07-14 Accepted date: 2020-11-23}

Biographies: Zhigang Huang, $\mathrm{PhD}$, Professor, research interest: food machinery and food processing, Email: huangzg@btbu.edu.cn; Xueying Wang, Master candidate, research interest: food machinery, Email: 965631898@qq.com; Shangyi Chi, Master candidate, research interest: food machinery, Email: 920312701@qq.com; Zhe Hua, Master, research interest: protein interaction in food industry, Email: 22584155@qq.com.

*Corresponding author: Chonghao Bi, PhD, Associated Professor, research interest: food emulsion, hydrocolloid and fractal analysis. School of Artificial Intelligence, Beijing Technology and Business University, Beijing 100048, China. Tel: +86-10-68985249, Email: bichonghao@btbu.edu.cn. the research object and proposed a new critical point for isotropy food gel and non-newton polymer systems. The results showed that when the higher harmonics increased to a certain value, the corresponding strain can be used as a new critical strain point, and it was demonstrated that the fractal dimension calculated from rheological fractal model using the new critical strain obtained from the Fourier transform analysis was closer to its actual value. Davis et al. ${ }^{[10]}$ studied fundamental rheological properties pertaining to aqueous peanut flour aggregation suspensions, both in the presence and absence of heating. They found the higher levels of fat in the dry powders inhibited the capacity of the aggregation suspensions to form gels. This data as a whole suggests the potential to collect the soluble fraction of such aggregation suspensions and use these solutions for appropriate applications, beverage systems requiring soluble protein. The insoluble material could then be utilized as a thickening agent in applications requiring an increase in viscosity. Chen et al. ${ }^{[11]}$ studied on mixed aggregation suspensions of flaxseed gum-peanut protein isolate (FG-PPI). The presence of flaxseed gum can reduce the gelling time and increase the gel strength of heat-induced PPI gels. These FG-PPI mixed gels are physical gels as storage modulus $\left(G^{\prime}\right)$ is much higher than loss modulus $\left(G^{\prime \prime}\right)$, and $G^{\prime}$ is dependent on frequency to some extent. The results demonstrated that the apparent viscosity of FG-PPI aggregation suspensions increased with the increase of FG concentration $(1-5 \mathrm{~g} / \mathrm{kg})$. These mixed aggregation suspensions showed a shear-thinning behavior which was represented well by the Herschel-Bulkley flow model $\left(R^{2} \geq 0.99\right)$. The addition of flaxseed gum has changed the rheological properties of PPI aggregation suspensions and gels. Kumar et al. ${ }^{[12]}$ studied the gelation properties of peanut globulin. The results showed that when the protein concentration was greater than $7.5 \% \mathrm{w} / \mathrm{v}$ and the value of $\mathrm{pH}$ was less than 3.8 , the peanut globulin can form reversible gel.

This study mainly researched the dynamic rheological 
properties of PPI aggregation suspension and its acid induced gels. The strain sweep, frequency sweep, and steady shear experiments were carried out on the PPI aggregation suspension. The time sweep, strain sweep and frequency sweep were carried out on the acid-induced PPI gels. The results from this study may provide better understanding of the dynamic rheological properties and the micro-interaction in PPI hybrid gel system, as well as allow better control of these complexes utilizing in food processing.

\section{Materials and methods}

\subsection{Materials}

Peanut protein isolate (S31067) was obtained from Shanghai Yuanye Bio-Technology Co., Ltd. (Shanghai, China). Rhodamine $\mathrm{B}$ (BS) was obtained from Beijing Yinghai fine chemical industry (Beijing, China). Glucono- $\delta$-lactone (GDL) was purchased from Beijing Wohai Technology Ltd. (Beijing, China).

\subsection{Methods}

2.2.1 Sample preparation

The preparation for the samples of PPI aggregation suspension:
$27 \mathrm{~g}$ PPI powder was dissolved in $100 \mathrm{~mL}$ deionized water $(\mathrm{pH}=6.7 \pm 0.3)$ at $20^{\circ} \mathrm{C}$ by stirring $2 \mathrm{~h}$ using a magnetic stirrer $(500$ $\mathrm{r} / \mathrm{min}$ ). When protein aggregation suspension was homogeneous, the PPI suspension was diluted to a concentration of $23 \%, 24 \%$, $25 \%, 26 \%$ and $27 \%$, respectively. Those suspensions at different concentrations were stored at $4{ }^{\circ} \mathrm{C}$ overnight.

Preparation for the samples of acid-induced PPI gel: 22 g PPI powder was dissolved in $100 \mathrm{~mL}$ deionized water $(\mathrm{pH}=6.7 \pm 0.3)$ at $20^{\circ} \mathrm{C}$ by stirring $2 \mathrm{~h}$ using a magnetic stirrer $(500 \mathrm{r} / \mathrm{min})$. This protein suspension was heated at $95^{\circ} \mathrm{C}$ for $30 \mathrm{~min}$ in water bath to denature the protein and then cooled down to $4^{\circ} \mathrm{C}$. PPI suspension was diluted to the concentration of $14 \%, 16 \%, 18 \%$, $20 \%$ and $22 \%$, respectively. The concentration was selected according to our previous study ${ }^{[13]}$. Those suspensions at different concentrations were stored at $4^{\circ} \mathrm{C}$ overnight. The completely denatured PPI suspension was taken $5 \mathrm{~mL}$ into a test tube, and then added with $0.1 \mathrm{~g}$ milled glucono- $\delta$-lactone (GDL). When GDL was completely dissolved, the sample was transferred to the rheometer as soon as possible.

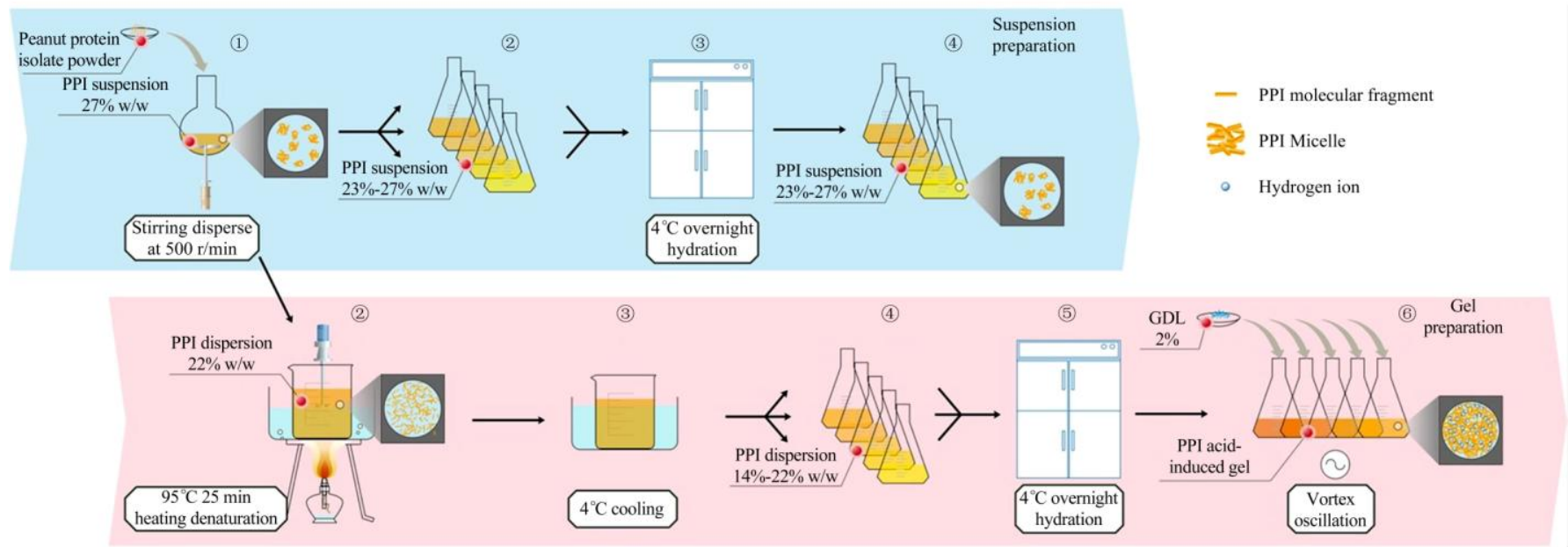

Figure 1 Preparation of PPI suspension and PPI acid-induced gel

\subsubsection{Rheological tests}

Both the formation of acid-induced PPI gel and measurement of rheological properties were carried out by AR2000ex rheometer (TA Instruments Ltd., Crawley, UK) with aluminum parallel plate geometry (40 mm diameter, $1 \mathrm{~mm}$ gap). The temperature was controlled by Peltier unit attached with water circulation system. GDL $(2 \% \mathrm{w} / \mathrm{v})$ in dry milled powder form was added into the stock suspension before the rheological tests. The samples $\left(20^{\circ} \mathrm{C}\right)$ were transferred on the bottom plate of the rheometer $\left(20^{\circ} \mathrm{C}\right.$, controlled by Peltier) and the gel was allowed to form in situ at $60^{\circ} \mathrm{C}$ for $40 \mathrm{~min}$. For all tests, the storage modulus $\left(G^{\prime}\right)$ and the loss modulus $\left(G^{\prime \prime}\right)$, loss tangent $\left(\tan \delta=G^{\prime \prime} / G^{\prime}\right)$ and viscosity were recorded by TA Rheology Advantage Data Analysis software V 5.4.7 (TA Instruments Ltd., Crawley, UK) accompanied with the AR rheometer ${ }^{[9]}$. All the rheological tests were conducted in triplicate.

\subsubsection{Gel formation}

The storage modulus $\left(G^{\prime}\right)$, loss modulus $\left(G^{\prime \prime}\right)$, and loss tangent $\left(\tan \delta=G^{\prime \prime} / G^{\prime}\right)$ were recorded once every $15 \mathrm{~s}$ during the gel formation process by time sweep test. The angular frequency was set at $1 \mathrm{~Hz}$, and the strain during gel formation was controlled at $1 \%$. A thin layer of silicone oil was applied on the edge of the samples to prevent the evaporation of water. The linear viscoelastic region (LVR) was determined by each sample's strain sweep test at a frequency of $1 \mathrm{~Hz}$ (data are shown in Figure 6). All the tests were performed within the LVR.

\subsubsection{Strain sweep test}

The temperature of strain sweep was controlled at $20^{\circ} \mathrm{C}$, and the frequency was set at $1 \mathrm{~Hz}$. The strain range was from $0.01 \%$ to $10 \%$. Each logarithmic interval took 10 points. The variation trends of the storage modulus and loss modulus of PPI suspension and its acid-induced gel with the strain increasing were recorded during the strain sweep. This article mainly studied on the rheological properties in LVR.

\subsubsection{Frequency sweep test}

The frequency sweep test was performed after the strain sweep test, and the sample was tested in LVR. In the experiment, the temperature was controlled at $20^{\circ} \mathrm{C}$, and the frequency was from 0.1 to $50 \mathrm{~Hz}$. The horizontal and vertical coordinates were taken as logarithmic points, and each logarithmic interval took 10 points. The strain of PPI suspension was set at $0.5 \%$ and that of acid-induced PPI gels was set at $0.1 \%$ in frequency sweep test (data was shown in Figure 2 and Figure 6 in order to keep the oscillatory amplitude within the LVR for all samples ${ }^{[14,15]}$. Data were recorded at a rate of 10 points per decade. Frequency $(f)$ dependence of $G^{\prime}$ and $G^{\prime \prime}$ were fitted using Power Law model equations given below:

$$
\begin{aligned}
G^{\prime} & =K^{\prime} \cdot f^{n \prime} \\
G^{\prime \prime} & =K^{\prime \prime} \cdot f^{n \prime \prime}
\end{aligned}
$$

where, $K^{\prime}$ and $K^{\prime \prime}$ are power law constants, $\mathrm{Pa} \cdot \mathrm{s}^{\mathrm{n}} ; f$ is frequency, $\mathrm{Hz}$; $n^{\prime}$ and $n^{\prime \prime}$ are frequency exponents, dimensionless ${ }^{[16]}$. 


\subsubsection{Steady state flow test}

The steady shear test was performed at $20^{\circ} \mathrm{C}$ over the shear rate range of $0.1-100 \mathrm{~s}^{-1[17]}$. The variation in apparent viscosity and shear stress as a function of shear rate were measured with this test. The variation trend of viscosity with shear rate was fitted by Power Law model and Carreau model shown as Equations (3) and (4).

$$
\eta=K^{\prime} \cdot \gamma^{n^{\prime}}
$$

where, $\eta$ is viscosity, $\mathrm{Pa} \cdot \mathrm{s} ; K^{\prime}$ is power law constants, $\mathrm{Pa} \cdot \mathrm{s}^{\mathrm{n}} ; \gamma$ is shear rate, $\mathrm{s}^{-1}$; and $n^{\prime}$ is shear rate dependence index, dimensionless $^{[16]}$.

$$
\eta=\frac{\left(\eta_{0}-\eta_{\infty}\right)}{\left[1+(\lambda \gamma)^{2}\right]^{\frac{1-n}{2}}}+\eta_{\infty}
$$

where, $\eta_{0}$ is the zero-shear rate viscosity, Pa.s; $\eta_{\infty}$ is the viscosity at infinite shear, $\mathrm{Pa} \cdot \mathrm{s} ; \lambda$ is the time constant; $n$ is flow behavior index, dimensionless $^{[18]}$.

\subsection{Data processing and statistical analysis}

Each experiment was carried out at least in triplicate and the results were presented in terms of mean \pm standard deviation. SPSS statistical package (SPSS 16.0, IBM Corporation, USA) was used to determine the significant different between two mean values at $95 \%$ confidence level $(p<0.05)$

\section{Results and discussion}

\subsection{Rheological properties of PPI suspension}

\subsubsection{Strain sweep test}

Figure 2a shows the effect of the strain on the storage modulus $\left(G^{\prime}\right)$ of PPI suspensions at different concentrations. As shown in Figure $2 \mathrm{a}$, when the strain was less than $1 \%$, the values of the $G^{\prime}$ of PPI suspensions at different concentrations did not change with the strain. While the strain was greater than $1 \%$, the $G^{\prime}$ began to decline. Because the high concentration of the suspension contains more solute, the formation of the suspension structure is more stable and has a high elasticity. What's more, the $G^{\prime}$ increases with the increase of the concentrations of PPI. In addition, Figure 2a shows that the PPI suspension value of the $G^{\prime}$ of the LVR is generally concentrated in the range of 10-1000 Pa. Also, it can be seen from Figure $2 \mathrm{a}$ that the difference of concentration is one percentage points, but the difference of modulus is very large. For example, the $G^{\prime}$ of the LVR of PPI at $24 \%$ concentration was $60 \mathrm{~Pa}$, while the $G^{\prime}$ of the LVR of PPI at $25 \%$ concentration was $100 \mathrm{~Pa}$. From Figure $2 \mathrm{a}$, it can be obtained that the LVR of PPI suspensions at different concentration and set a suitable strain, which guarantees that both the frequency sweep and steady state shear flow test are carried out under this strain, preventing the larger strain from damaging the sample and affecting the experimental results. As a result, $0.5 \%$ could be selected as the fixed strain of other dynamic rheological tests. Finally, the strain value corresponding to the boundary point of the transition from the LVR to the non-LVR is the critical strain.

It can be seen from Figure 2a that the critical strain of PPI suspensions with different concentrations decreased with the increase of concentration.

Figure $2 b$ shows the effect of the strain on the loss modulus $\left(G^{\prime \prime}\right)$ of PPI suspensions at different concentrations. The change trends of the $G^{\prime \prime}$ of PPI suspension with the strain are similar. When the strain was less than $2 \%$, the values of the $G^{\prime \prime}$ of PPI suspension at different concentrations didn't change with the strain. When the strain was greater than $2 \%$, the $G^{\prime \prime}$ began to decrease. Because the high concentration of the suspension contained more solute, the formation of the structure was more stable and had a high viscosity, thus the $G^{\prime \prime}$ increased with an increase of the concentration of PPI. In addition, Figure $2 b$ showed that the value of the loss modulus of the LVR is generally concentrated in the range of 1-100 Pa. The $G^{\prime}$ of the PPI suspension at $23 \%$ concentration is close to $30 \mathrm{~Pa}$ in Figure $2 \mathrm{a}$, while the $G^{\prime \prime}$ of the suspension at $23 \%$ is between $6.8 \mathrm{~Pa}$ in Figure $2 \mathrm{~b}$. The value of the $G^{\prime \prime}$ of the LVR was lower than that of the $G^{\prime}$, which showed that the elasticity of PPI suspension was dominant.

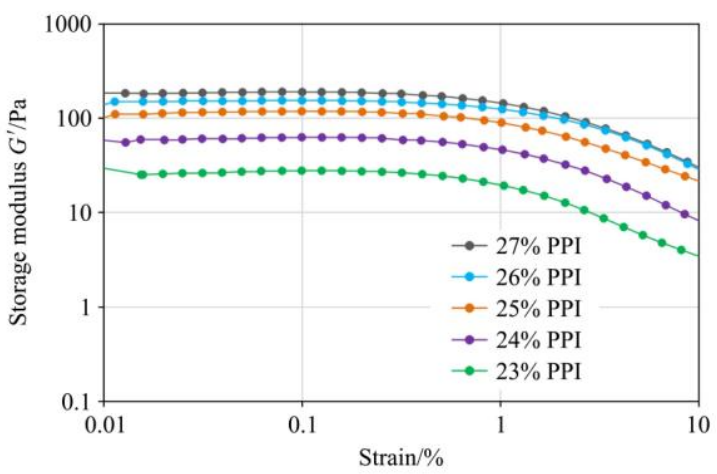

a. Storage modulus

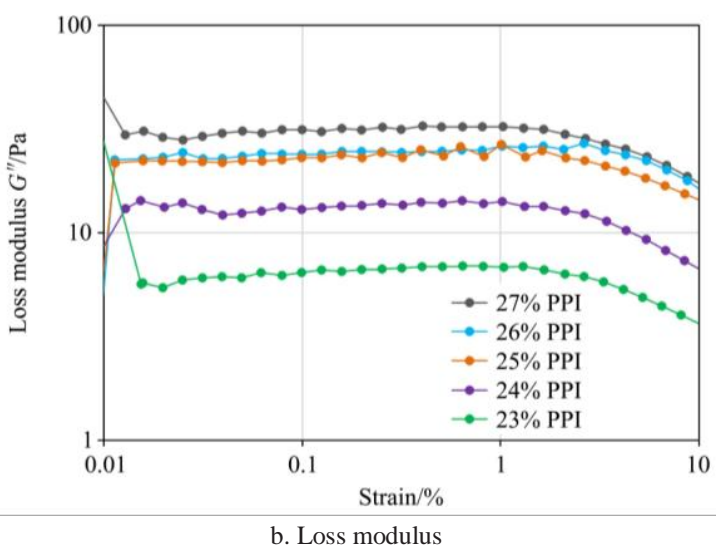

Figure 2 Effects of the strain on (a) storage modulus $\left(G^{\prime}\right)$ and (b) loss modulus $\left(G^{\prime \prime}\right)$ of PPI suspensions at different concentrations

\subsubsection{Frequency sweep test}

Figure $3 \mathrm{a}$ shows the effect of the frequency on the storage modulus $\left(G^{\prime}\right)$ of PPI suspensions at different concentrations. Frequency sweep was controlled in the range of $0.1-10 \mathrm{~Hz}$, and the $G^{\prime}$ of PPI suspension at different concentrations increased with the increasing frequency. The $G^{\prime}$ of PPI suspension increased with the increase of their concentration. Figure $3 \mathrm{~b}$ shows the effect of the frequency on the loss modulus $\left(G^{\prime \prime}\right)$ of PPI suspensions at different concentrations. In the frequency range of $0.1-50 \mathrm{~Hz}$, the $G^{\prime \prime}$ increases with the increasing frequency. It is shown that the higher the concentration of PPI suspension is, the higher the $G^{\prime \prime}$ of the suspension is. Compared with the data of Figure $3 a$, Figure $3 b$ shows that the $G^{\prime}$ of PPI suspension is always greater than the $G^{\prime \prime}$, suggesting that the elasticity of the sample in the LVR exhibits greater elasticity than viscosity.

Table 1 shows that with the increase of concentration, $K^{\prime}$ increases gradually, indicating that the $G^{\prime}$ increases, and with the increase of concentration, $K^{\prime \prime}$ increases gradually, which indicates that the $G^{\prime \prime}$ increases. The value of $n^{\prime}$ and $n^{\prime \prime}$ decreases gradually with increasing concentration, which indicates that the slope of frequency sweep image decreases with the increase of protein concentration, and the frequency dependence of the $G^{\prime}$ and $G^{\prime \prime}$ decreases with the increase of protein concentration. Also, the Power Law model can be used to fit the image well. 


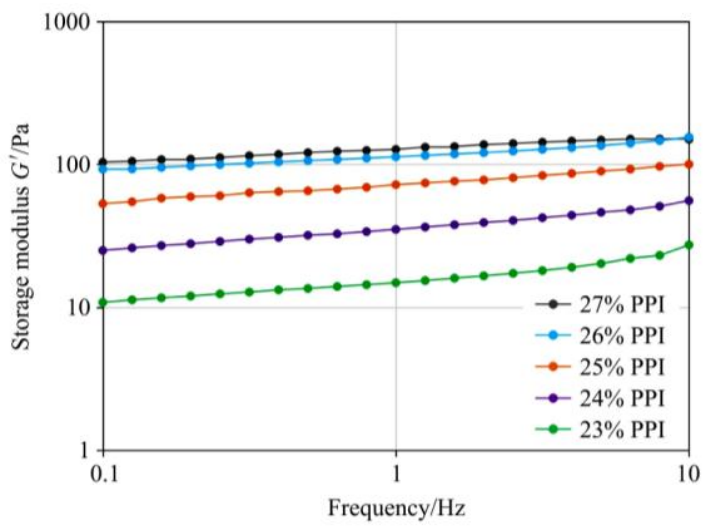

a. Storage modulus

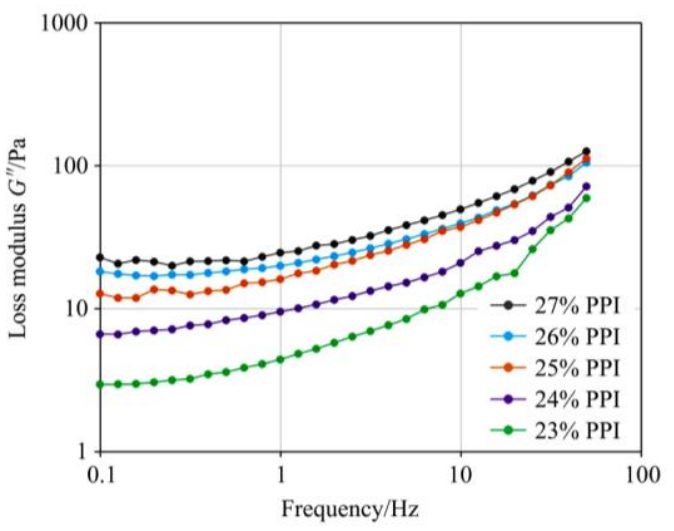

b. Loss modulus

Figure 3 Effects of the frequency on (a) storage modulus $\left(G^{\prime}\right)$ and (b) loss modulus $\left(G^{\prime \prime}\right)$ of PPI suspensions at different concentrations

Table 1 Effect of concentration of PPI suspension on its Power Law parameters $\left(K^{\prime}\right.$ and $\left.n^{\prime}\right)$ and $\left(K^{\prime \prime}\right.$ and $\left.n^{\prime \prime}\right)$ in frequency sweep test

\begin{tabular}{|c|c|c|c|c|c|c|}
\hline \multirow{2}{*}{ PPI concentration $/ \%$} & \multicolumn{3}{|c|}{$G^{\prime}=K^{\prime} \cdot f^{n^{\prime}}$} & \multicolumn{3}{|c|}{$G^{\prime \prime}=K^{\prime \prime} \cdot f^{n^{\prime \prime}}$} \\
\hline & $K^{\prime} / \mathrm{Pa} \cdot \mathrm{s}^{\mathrm{n}}$ & $n^{\prime}$ & $R^{2}$ & $K^{\prime \prime} / \mathrm{Pa} \cdot \mathrm{s}^{\mathrm{n}}$ & $n^{\prime \prime}$ & $R^{2}$ \\
\hline 23 & $15.464 \pm 0.248^{\mathrm{e}}$ & $0.190 \pm 0.011^{\mathrm{a}}$ & 0.943 & $1.648 \pm 0.318^{\mathrm{e}}$ & $0.892 \pm 0.055^{\mathrm{a}}$ & 0.958 \\
\hline 24 & $35.757 \pm 0.237^{\mathrm{d}}$ & $0.167 \pm 0.005^{\mathrm{b}}$ & 0.987 & $6.699 \pm 0.830^{\mathrm{d}}$ & $0.557 \pm 0.038^{\mathrm{b}}$ & 0.932 \\
\hline 25 & $72.391 \pm 0.222^{\mathrm{c}}$ & $0.134 \pm 0.002^{\mathrm{d}}$ & 0.995 & $13.116 \pm 1.245^{\mathrm{c}}$ & $0.511 \pm 0.030^{\mathrm{b}}$ & 0.948 \\
\hline 26 & $114.734 \pm 0.590^{\mathrm{b}}$ & $0.109 \pm 0.004^{\mathrm{c}}$ & 0.980 & $18.111 \pm 1.476^{\mathrm{b}}$ & $0.404 \pm 0.027^{\mathrm{c}}$ & 0.922 \\
\hline 27 & $127.599 \pm 0.438^{\mathrm{a}}$ & $0.087 \pm 0.002^{\mathrm{e}}$ & 0.986 & $22.414 \pm 1.679^{\mathrm{a}}$ & $0.405 \pm 0.025^{\mathrm{c}}$ & 0.934 \\
\hline
\end{tabular}

Note: ${ }^{\text {a,b,c,d,e }}$ values with different superscript are significantly different $(p<0.05)$

\subsubsection{Steady state shear flow test}

Figure 4 shows the effect of the shear rate on the viscosity of PPI suspensions at different concentrations. The apparent viscosity of PPI suspension at different concentrations decreases with the shear rate increases, suggesting a thinning behavior of the shear. As shown in Figure 4, the steady state shear curve of the suspension at $23 \%$ and $24 \%$ concentration yields a local maximum at $1.5 \mathrm{~s}^{-1}$. This may be resulted from that the concentrations of protein suspension is too low, showing an unstable suspension structure. As the shear rate increases to a certain value, the apparent viscosity increases instantaneously, whereas the high concentration of suspensions is more stable. It can be seen from the Figure 4, when the shear rate is constant, the higher the concentration is, the greater the apparent viscosity of PPI suspension is.

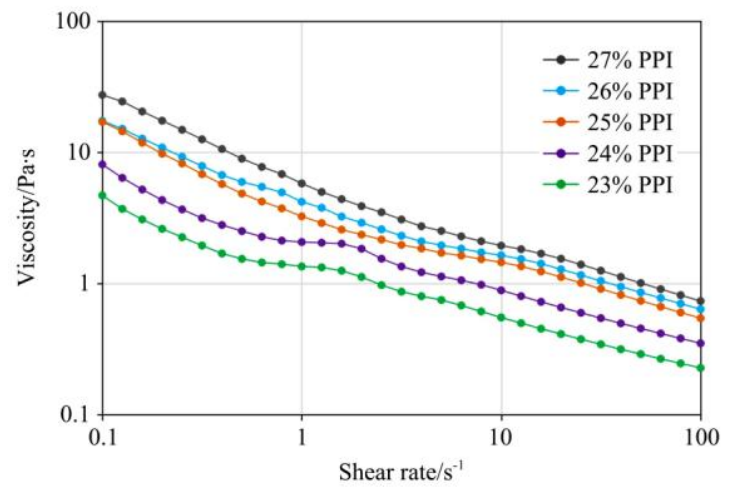

Figure 4 Effect of the shear rate on the viscosity of PPI suspensions at different concentration

As shown in Figure 4, in the shear rate range of $0.1-2 \mathrm{~s}^{-1}$, the steady shear curve is not a straight line, having a certain radian. So the curve can be fitted by Carreau model. In the shear rate range of 2-100 $\mathrm{s}^{-1}$, the steady state shear curve is closer to a line, so the Power Law model is used to fit it.

As shown in Table 2, the Carreau model can be well fitted in the shear rate range of $0.1-2 \mathrm{~s}^{-1}$. It was shown that the apparent viscosity at zero shear rate decreased with the increase of concentration. And $\eta_{\infty}$ increased gradually with the increase of concentration. It suggested that when the shear rate was infinite, the apparent viscosity increased with the increase of concentration. Furthermore, $\lambda$ decreased with the increase of concentration. The value of $n$ did not change significantly.

Table 2 Effects of the concentration of PPI suspension on Carreau model fitting parameters in steady state shear flow test

\begin{tabular}{cccccc}
\hline $\begin{array}{c}\text { PPI } \\
\text { concentration/\% }\end{array}$ & $\eta_{0} / \mathrm{Pa} \cdot \mathrm{s}$ & $\eta_{\infty} / \mathrm{Pa} \cdot \mathrm{s}$ & $\lambda / \mathrm{s}$ & $n$ & $R^{2}$ \\
\hline 23 & $15.212 \pm 1.978$ & $1.148 \pm 0.069$ & $38.182 \pm 3.774$ & $1.301 \pm 0.149$ & 0.999 \\
24 & $20.946 \pm 1.341$ & $1.721 \pm 0.053$ & $23.470 \pm 3.232$ & $1.295 \pm 0.062$ & 1.000 \\
25 & $34.073 \pm 3.002$ & $1.901 \pm 0.208$ & $16.935 \pm 2.620$ & $1.110 \pm 0.067$ & 1.000 \\
26 & $29.046 \pm 2.816$ & $3.029 \pm 0.378$ & $13.666 \pm 2.929$ & $1.127 \pm 0.130$ & 0.999 \\
27 & $41.708 \pm 2.536$ & $2.764 \pm 0.702$ & $12.071 \pm 1.964$ & $1.010 \pm 0.108$ & 1.000 \\
\hline
\end{tabular}

As can be seen from Table 3, within the range of 2-100 $\mathrm{s}^{-1}$, the Power Law model can be well fitted. With the increase of concentration, $K^{\prime}$ increased gradually, indicating that the storage modulus increased. The absolute value of $n^{\prime}$ didn't change significantly, which showed that the shear rate dependence of apparent viscosity was not significant with the change of concentration in steady state shear flow test.

Table 3 Effects of the concentration of PPI suspension on its Power Law fitting parameters $K^{\prime}$ and $n^{\prime}$ in steady state shear flow test

\begin{tabular}{cccc}
\hline \multirow{2}{*}{$\begin{array}{c}\text { PPI concentration } \\
\text { \% }\end{array}$} & \multicolumn{3}{c}{$\eta=K^{\prime} \cdot \gamma^{n^{\prime}}$} \\
\cline { 2 - 4 } & $K^{\prime} / \mathrm{Pa} \cdot \mathrm{s}^{\mathrm{n}}$ & $n^{\prime}$ & $R^{2}$ \\
\hline 23 & $1.473 \pm 0.013$ & $-0.423 \pm 0.006$ & 0.997 \\
24 & $2.326 \pm 0.036$ & $-0.424 \pm 0.010$ & 0.993 \\
25 & $3.054 \pm 0.039$ & $-0.349 \pm 0.007$ & 0.994 \\
26 & $3.861 \pm 0.071$ & $-0.388 \pm 0.011$ & 0.988 \\
27 & $5.295 \pm 0.072$ & $-0.433 \pm 0.009$ & 0.994 \\
\hline
\end{tabular}




\subsection{Rheological properties of acid-induced PPI gels}

\subsubsection{Gel formation}

Figure 5 shows the variation of storage modulus $\left(G^{\prime}\right)$ of PPI with time gel. The temperature was controlled at $60^{\circ} \mathrm{C}$ with $40 \mathrm{~min}$ to form gel. What's more, the strain was set at $0.1 \%$, and the oscillation frequency was set at $1 \mathrm{~Hz}$. Although the concentrations of all the samples were different, the trends of the $G^{\prime}$ with the increase of time were all similar, and the increasing rate of the $G^{\prime}$ was decreasing with the increase of time. After reaching a certain period of time, the $G^{\prime}$ did not increase with the increase of time. It can be seen from Figure 5 that the $G^{\prime}$ of PPI gels did not increase any more when the gelation time was $40 \mathrm{~min}$, which indicated that the gel formation time of acid-induced PPI gel was at least $40 \mathrm{~min}$, and that of soybean protein isolate was $30 \mathrm{~min}$. Therefore, it takes longer for the peanut protein to form gel. What's more, there are other proteins reported to show a similar trend in the formation of a gel like PPI, such as soybean protein, whey protein and egg white protein $^{[19-21]}$. In addition, with the increasing of the concentration of suspension, the $G^{\prime}$ of the gel increases, indicating that the elasticity of acid-induced $G^{\prime}$ gel increases.

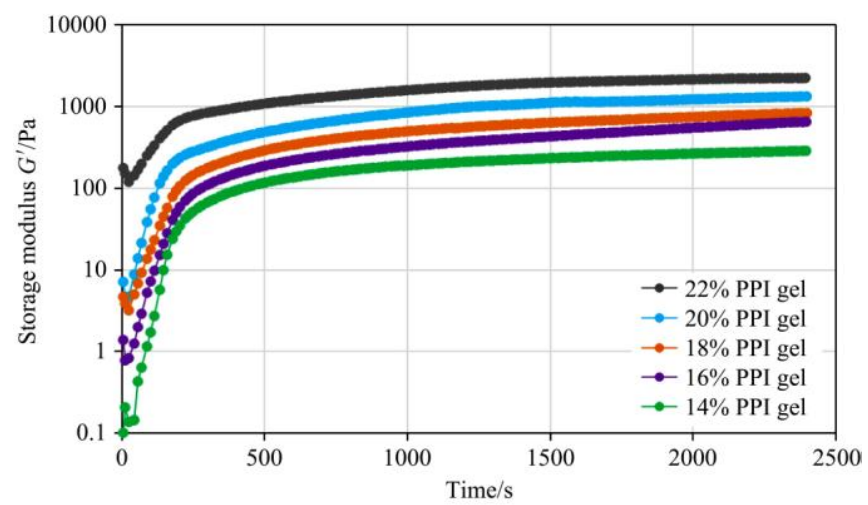

Figure 5 Variation of storage modulus $\left(G^{\prime}\right)$ of PPI with time gel at $60^{\circ} \mathrm{C}$

\subsubsection{Strain sweep test}

Figure 6 shows the effect of the strain on the storage modulus $\left(G^{\prime}\right)$ of acid-induced PPI gels at different concentrations. The setting temperature of the sample was $20^{\circ} \mathrm{C}$, and the range of strain was from $0.01 \%$ to $10 \%$, and the frequency was $1 \mathrm{~Hz}$. It can be seen from Figure 6 that when the strain is less than $1 \%$, the value of the $G^{\prime}$ remains constant. With the increase of the strain, the $G^{\prime}$ decreases, and the trend of loss modulus $G^{\prime \prime}$ is similar to that of the

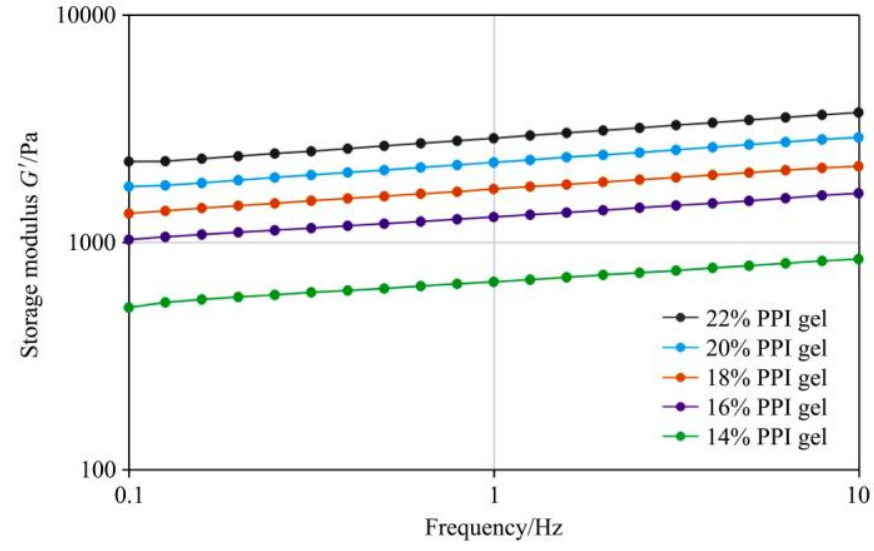

a. Storage modulus storage modulus $G^{\prime}$ (data not shown in the figure). According to the network model given by Hyun et al., acid-induced PPI gels shows a typical Type I behavior (strain thinning), which is similar to the behavior observed in soybean protein isolate gels ${ }^{[22]}$. For this type of network, the creation rate parameter is $a<0$ and the loss rate parameter is $b>0^{[22]}$, which means that PPI gel gets easily to be broken down and there is a very small opportunity for the protein molecules to re-establish the network.

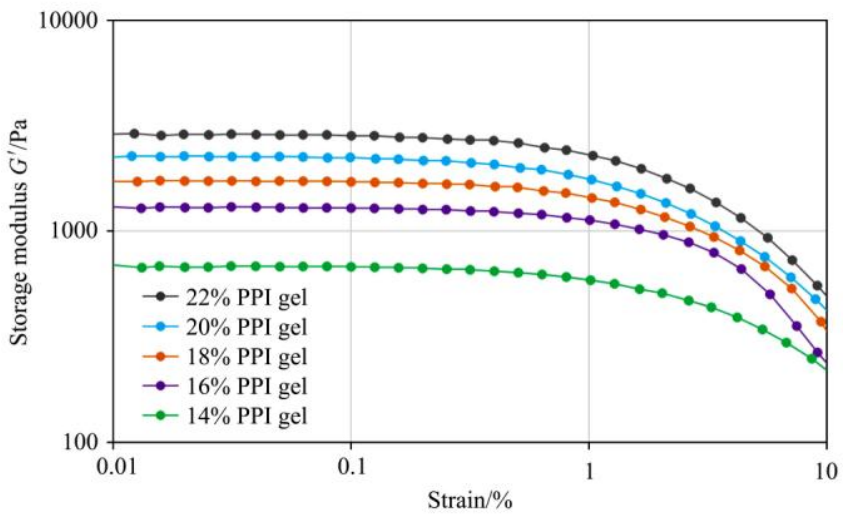

Figure 6 Effects of the strain on storage modulus $\left(G^{\prime}\right)$ of acid-induced PPI gels at different concentrations

\subsubsection{Frequency sweep test}

Figure 7 shows the effect of the frequency on the storage modulus $\left(G^{\prime}\right)$ and the loss modulus $\left(G^{\prime \prime}\right)$ of acid-induced PPI gels at different concentrations. The value of $G^{\prime}$ and $\mathrm{G}^{\prime \prime}$ increases with the increase of frequency. It is suggested that as the frequency increases, both its elasticity and viscosity increase. When the frequency is fixed, the $G^{\prime}$ of acid-induced PPI gels increases with the increase of concentration, indicating that when the frequency is constant, both elasticity and viscosity increase with the increase of concentration. The trends of $G^{\prime}$ and $G^{\prime \prime}$ with frequency can be well fitted by the Power Law model, and the data are shown in Table 4.

As can be seen from Table 4, with the increase of concentration, the value of $K^{\prime}$ and $K^{\prime \prime}$ increases gradually, which indicates that the $G^{\prime}$ and $G^{\prime \prime}$ of PPI gels increases. $n^{\prime}$ also increased gradually, indicating that the higher the concentration is, the higher the frequency dependence of the $G^{\prime}$ is. The change of $n^{\prime \prime}$ was not significant, indicating that the frequency dependence of the loss modulus was not significant with concentration.

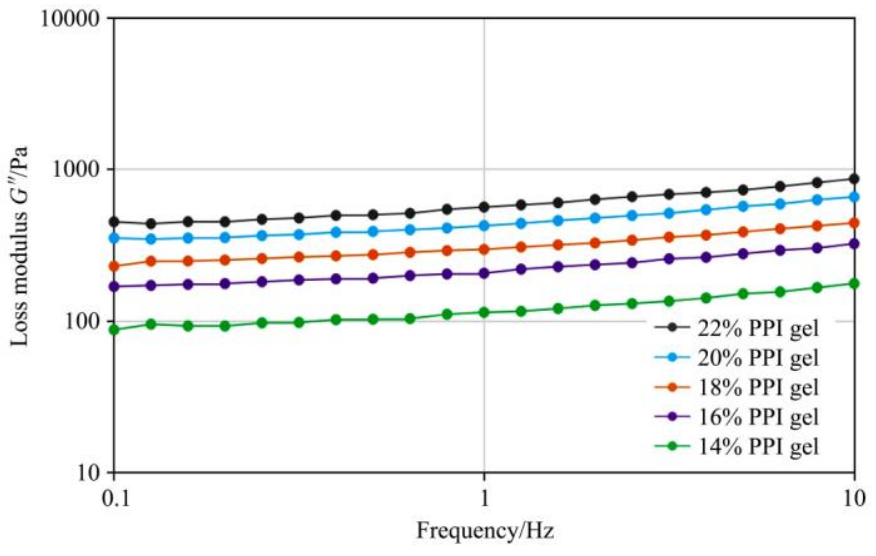

b. Loss modulus

Figure 7 Effects of the frequency on (a) storage modulus $\left(G^{\prime}\right)$ and (b) loss modulus $\left(G^{\prime \prime}\right)$ of acid-induced PPI gels at different concentrations 
Table 4 Effects of the concentration of acid-induced PPI gels on its Power Law parameters $\left(K^{\prime}\right.$ and $\left.n^{\prime}\right)$ and $\left(K^{\prime \prime}\right.$ and $\left.n^{\prime \prime}\right)$ in frequency sweep test

\begin{tabular}{|c|c|c|c|c|c|c|}
\hline \multirow{2}{*}{$\begin{array}{c}\text { PPI concentration } \\
1 \%\end{array}$} & \multicolumn{3}{|c|}{$G^{\prime}=K^{\prime} \cdot f^{n^{\prime}}$} & \multicolumn{3}{|c|}{$G^{\prime \prime}=K^{\prime \prime} \cdot f^{n^{\prime \prime}}$} \\
\hline & $K^{\prime} / \mathrm{Pa} \cdot \mathrm{s}^{\mathrm{n}}$ & $n^{\prime}$ & $R^{2}$ & $K^{\prime \prime} / \mathrm{Pa} \cdot \mathrm{s}^{\mathrm{n}}$ & $n^{\prime \prime}$ & $R^{2}$ \\
\hline 14 & $670.903 \pm 0.940^{\mathrm{e}}$ & $0.101 \pm 0.001^{\mathrm{c}}$ & 0.998 & $116.503 \pm 1.102^{\mathrm{e}}$ & $0.153 \pm 0.007^{\mathrm{a}}$ & 0.967 \\
\hline 16 & $1296.473 \pm 1.120^{\mathrm{d}}$ & $0.101 \pm 0.001^{\mathrm{c}}$ & 0.999 & $217.645 \pm 1.794^{\mathrm{d}}$ & $0.148 \pm 0.006^{\mathrm{a}}$ & 0.973 \\
\hline 18 & $1712.580 \pm 1.050^{\mathrm{c}}$ & $0.104 \pm 0.000^{\mathrm{b}}$ & 1.000 & $306.540 \pm 2.208^{\mathrm{c}}$ & $0.141 \pm 0.005^{\mathrm{a}}$ & 0.977 \\
\hline 20 & $2247.870 \pm 1.337^{\mathrm{b}}$ & $0.111 \pm 0.000^{\mathrm{a}}$ & 1.000 & $441.654 \pm 4.044^{\mathrm{b}}$ & $0.151 \pm 0.006^{\mathrm{a}}$ & 0.968 \\
\hline
\end{tabular}

Note: ${ }^{\mathrm{a}, \mathrm{b}, \mathrm{c}, \mathrm{d}, \mathrm{e}}$ values with different superscript were significantly different $(p<0.05)$.

\section{Conclusions}

Rheological properties of PPI suspension were obtained by strain sweep, frequency sweep and steady state shear flow tests. The critical strain of PPI suspensions decreases with the increase of concentrations. Both the $G^{\prime}$ and the $G^{\prime \prime}$ of PPI suspensions fit the Power Law model. It was also observed that the elasticity of the sample in the LVR was greater than viscosity. PPI suspension has a shear thinning behavior, also the viscosity-shear rate curve can fit the Carreau model very well. For the acid-induced PPI gel, the gel formation time obtained was at least $40 \mathrm{~min}$. With the increase of the concentration of suspension, the elasticity of acid-induced PPI gel multiplied. For acid-induced PPI gels, the gel system showed a typical Type I behavior (strain thinning), which means that the gel gets easily broken down and there is a very small opportunity for the protein molecules to re-establish the network. The Power Law model fitting parameters indicated that there was strong positive correlation relationship between frequency dependence and the PPI concentration of the gel.

\section{Acknowledgements}

This research project was supported by the 2021 Postgraduate Research Ability Improvement Program BTBU, General Project of Scientific Research Program of Beijing Education Commission (Grant No. KM201910011003, KM201910011001) and Joint Program of Beijing Natural Science Foundation Committee and Beijing Education Committee (Grant No. KZ201810011017). This research project was also supported by Beijing Excellent Talent Training Project (Grant No. 2017000020124G100).

\section{[References]}

[1] Jamdar S N, Rajalakshmi V, Pednekar M D, Juan F, Yardi V, Sharma A. Influence of degree of hydrolysis on functional properties, antioxidant activity and ACE inhibitory activity of peanut protein hydrolysate. Food Chemistry, 2010; 121(1): 178-184.

[2] Ghatak S K, Sen K. Peanut proteins: Applications, ailments and possible remediation. Industrial \& Engineering Chemistry Research, 2013; 19: 369-374.

[3] He X H, Liu H Z, Liu L, Zhao G L, Wang Q, Chen Q L. Effects of high pressure on the physicochemical and functional properties of peanut protein isolates. Food Hydrocolloids, 2014; 36: 123-129.

[4] Liu Y, Zhao G L, Zhao M M, Ren J Y, Yang B. Improvement of functional properties of peanut protein isolate by conjugation with dextran through Maillard reaction. Food Chemistry, 2012; 131(3): 901-906.

[5] Dong X H, Zhao M M, Shi J, Yang B, Li J, Luo D H, et al. Eff ects of combined high-pressure homogenization and enzymatic treatment on extraction yield, hydrolysis and function properties of peanut proteins. Innovative Food Science and Emerging Technologies, 2011; 12(4): 478-483.

[6] Suknark K, Lee J, Eitenmiller R R, Phillips R D. Stability of tocopherols and rentinyl palmitate in snack extrudates. Journal of Food Science, 2001 66(6): 897-902.

[7] Jangchud A, Chinnan M S. Properties of peanut protein film: sorption isotherm and plasticizer effect. Lebensmittel-Wissenschaft und-Technologie-Food Science and Technology, 1999; 32: 89-94.

[8] Liu D C, Zhang W N, Hu X H. Study on preparation and functional properties of peanut protein. Journal of Wuhan Polytechnic University, 2001; 4: 1-4.

[9] Bi C H, Li L T, Zhu Y D, Liu Y D, Wu M, Li G, et al. Effect of high-speed shear on the non-linear rheological properties of SPI/ $\kappa$-carrageenan hybrid dispersion and fractal analysis. Journal of Food Engineering, 2018; 218(Feb): 80-87.

[10] Davis J P, Gharst G, Sanders T H. Some rheological properties of aqueous peanut flour dispersions. Journal of Texture Studies, 2007; 38: 253-272.

[11] Chen C, Huang X, Wang L J, Li D, Adhikar B. Effect of flaxseed gum on the rheological properties of peanut protein isolate dispersions and gels. LWT-Food Science and Technology, 2016; 74: 528-533.

[12] Kumar K D N, Nandi P, Rao M S N. Reversible gelation of arachin. International Journal of Peptide Protein Research, 1980; 15: 67-72.

[13] Bi C H, Zhang M, Sun D Y, Hua Z, Zhu Y D, Liu Y D, et al. A novel critical point for isotropic gel in rheological-fractal model. Journal of Food Engineering, 2019; 244: 40-46.

[14] Bi C H, Wang P L, Sun D Y, Yan Z M, Liu Y, Huang Z G, et al. Effect of high-pressure homogenization on gelling and rheological properties of soybean protein isolate emulsion gel. Journal of Food Engineering, 2020; 277: 109923. doi: 10.1016/j.jfoodeng.2020.109923.

[15] Bi C H, Yan Z M, Wang P L, Alkhatib A, Zhu J Y, Zou H C, et al. Effect of high-pressure homogenization treatment on the rheological properties of citrus peel fiber/corn oil emulsion. Journal of the Science of Food and Agriculture, 2020; 100(9): 10398. doi: 10.1002/jsfa.10398.

[16] Özkan N, Xin H, Chen X D. Application of a depth sensing indentation hardness test to evaluate the mechanical properties of food materials. Journal of Food Science, 2002; 67(5): 1814-1820.

[17] Steffe J F. Rheological methods in food process engineering. East Lansing: Freeman Press, 1996; 428 p.

[18] Bi C H, Li D, Wang L J, Adhikari B. Viscoelastic properties and fractal analysis of acid-induced SPI gels at different ionic strength. Carbohydrate Polymers, 2013; 92(1): 98-105.

[19] Dosunmu I T, Shah S N. Pressure drop predictions for laminar pipe flow of carreau and modified power law fluids. The Canadian Journal of Chemical Engineering, 2015; 93(5): 929-934.

[20] Eleya M M O, Ko S, Gunasekaran S. Scaling and fractal analysis of viscoelastic properties of heat-induced protein gels. Food Hydrocolloids, 2004; 18(2): 315-323.

[21] Ikeda S, Foegeding E A, Hagiwara T. Rheological study on the fractal nature of the protein gel structure. Langmuir, 1999; 15(25): 8584-8589.

[22] Hyun K, Kim S H, Ahn K H, Lee S J. Large amplitude oscillatory shear as a way to classify the complex fluids. Journal of Non-Newtonian Fluid Mechanics, 2002; 107(1-3): 51-65. 